\title{
Resection and permanent intracranial brachytherapy using modular, biocompatible cesium-131 implants: results in 20 recurrent, previously irradiated meningiomas
}

\author{
David G. Brachman, MD, ${ }^{1}$ Emad Youssef, MD, ${ }^{1}$ Christopher J. Dardis, MD, ${ }^{3}$ Nader Sanai, MD, ${ }^{2}$ \\ Joseph M. Zabramski, MD, ${ }^{2}$ Kris A. Smith, MD, ${ }^{2}$ Andrew S. Little, MD, ${ }^{2}$ Andrew G. Shetter, MD, ${ }^{2}$ \\ Theresa Thomas, MS, ${ }^{4}$ Heyoung L. McBride, MD, MS, ${ }^{5}$ Stephen Sorensen, PhD, ${ }^{4}$ \\ Robert F. Spetzler, MD, ${ }^{2}$ and Peter Nakaji, MD²
}

\begin{abstract}
Departments of ${ }^{1}$ Radiation Oncology, ${ }^{2}$ Neurosurgery, and ${ }^{3}$ Neurology, Barrow Neurological Institute, and ${ }^{4}$ St. Joseph's Hospital and Medical Center, Phoenix, Arizona; and 5Lovelace Medical Center, Albuquerque, New Mexico
\end{abstract}

\begin{abstract}
OBJECTIVE Effective treatments for recurrent, previously irradiated intracranial meningiomas are limited, and resection alone is not usually curative. Thus, the authors studied the combination of maximum safe resection and adjuvant radiation using permanent intracranial brachytherapy $(\mathrm{R}+\mathrm{BT})$ in patients with recurrent, previously irradiated aggressive meningiomas.
\end{abstract}
METHODS Patients with recurrent, previously irradiated meningiomas were treated between June 2013 and October 2016 in a prospective single-arm trial of R+BT. Cesium-131 (Cs-131) radiation sources were embedded in modular col- lagen carriers positioned in the operative bed on completion of resection. The Cox proportional hazards model with this treatment as a predictive term was used to model its effect on time to local tumor progression.

RESULTS Nineteen patients (median age 64.5 years, range 50-78 years) with 20 recurrent, previously irradiated tumors were treated. The WHO grade at R+BT was I in $4(20 \%)$, II in $14(70 \%)$, and III in $2(10 \%)$ cases. The median number of prior same-site radiation courses and same-site surgeries were 1 (range 1-3) and 2 (range 1-4), respectively; the median preoperative tumor volume was $11.3 \mathrm{~cm}^{3}\left(\right.$ range $\left.0.9-92.0 \mathrm{~cm}^{3}\right)$. The median radiation dose from BT was 63 Gy (range 54-80 Gy). At a median radiographic follow-up of 15.4 months (range $0.03-47.5$ months), local failure (within $1.5 \mathrm{~cm}$ of the implant bed) occurred in 2 cases $(10 \%)$. The median treatment-site time to progression after R+BT has not been reached; that after the most recent prior therapy was 18.3 months (range 3.9-321.9 months; HR 0.17, $p=0.02$, logrank test). The median overall survival after R+BT was 26 months, with 9 patient deaths ( $47 \%$ of patients). Treatment was well tolerated; 2 patients required surgery for complications, and 2 experienced radiation necrosis, which was managed medically.

CONCLUSIONS R+BT utilizing Cs-131 sources in modular carriers represents a potentially safe and effective treatment option for recurrent, previously irradiated aggressive meningiomas.

https://thejns.org/doi/abs/10.3171/2018.7.JNS18656

KEYWORDS brachytherapy; cesium-131; implants; intraoperative; meningiomas; recurrent; oncology

$\mathrm{R}$ ESECTION remains the mainstay of high-grade meningioma treatment. Various external-beam radiation therapy (EBRT) modalities (including stereotactic or fractionated intensity-modulated radiation) are used when disease persists, progresses, or recurs despite surgery. ${ }^{24,32}$ However, treatment options are limited for patients with aggressive meningiomas that progress locally despite previous radiation, and no routinely effective therapy is available in this setting. ${ }^{24,32}$ Surgery alone for recurrent aggressive meningioma is not usually curative, ${ }^{32}$ and systemic therapy is investigational. ${ }^{24}$ Repeating any form of radiation can increase the risk of brain injury; ${ }^{5}$ this risk is typically mitigated by administering additional radiation at a reduced and potentially less effective dose. ${ }^{27,37}$

ABBREVIATIONS BT = brachytherapy; Cs = cesium; CTCAE = Common Terminology Criteria for Adverse Events; EBRT = external-beam radiation therapy; GTR = grosstotal resection; HR = hazard ratio; NGTR = near gross-total resection ( $\geq 90 \%) ; \mathrm{PFS}=$ progression-free survival; R+BT = resection and BT; STR = subtotal resection; TTP = time to progression.

SUBMITTED March 9, 2018. ACCEPTED July 16, 2018.

INCLUDE WHEN CITING Published online December 21, 2018; DOI: 10.3171/2018.7.JNS18656. 
Whereas resection alone is generally insufficient in recurrent, previously irradiated meningiomas, it can provide symptom relief, and the extent of resection correlates with the likelihood of control. ${ }^{2}$ Combining resection with adjuvant re-irradiation via brachytherapy (BT) represents a theoretically attractive therapeutic option for several reasons. Early postresection initiation of radiation-when residual tumor burden is minimal-could evince a relatively higher therapeutic ratio in rapidly proliferating tumors. ${ }^{6,15}$ BT using a low-energy (i.e., short-range) isotope exposes less normal tissue to radiation than EBRT techniques, ${ }^{31,34}$ and it may limit neurocognitive deficits ${ }^{28,33}$ while allowing a higher local radiation dose. ${ }^{34}$ Radiation source placement under intraoperative visualization also should allow a more precise identification of the area at risk than the postoperative imaging utilized for EBRT treatment. ${ }^{20,29}$

BT is a current standard-of-care treatment for many non-central nervous system tumors, ${ }^{21}$ with use for brain tumors dating back to $1914 .{ }^{36}$ Contemporary brain tumor BT series have typically used temporary or permanent iodine-125 (I-125) radioactive sources encapsulated in small titanium capsules (i.e., "seeds"). Intracranial seeds are most commonly used in high-grade gliomas, with studies frequently finding high rates of brain necrosis and reoperation, ${ }^{7,30}$ although poor outcomes were not universal. ${ }^{19,21}$

To overcome drawbacks of previous central nervous system BT treatment paradigms, we developed a modular collagen-based seed carrier to hold multiple radiation sources in precise positions. This permanently implanted device functions as a 3D spacer that optimizes interseed spacing and prevents seeds from deleterious direct contact with the brain, while facilitating rapid completion of the implant by allowing simultaneous placement of multiple seeds.

We chose the isotope cesium-131 (Cs-131) because of its relatively short half-life ( $t_{1 / 2}=9.7$ days). A short $t_{1 / 2}$ is postulated to offer a biological advantage in treating tumors with relatively short doubling times, with $88 \%$ of the radiation dose delivered within 30 days versus 200 days for I-125. ${ }^{3}$ The shorter $t_{1 / 2}$ also markedly lessens the duration of radiation exposure to caregivers compared with I-125. ${ }^{27}$ The location and spacing of seeds within the collagen carrier was designed specifically for the $30-\mathrm{keV}$ emitting energy of Cs-131. We present our initial safety and efficacy experience with resection and permanently implanted intracranial BT (R+BT) as a salvage treatment for recurrent, previously irradiated aggressive meningiomas.

\section{Methods \\ Patient Population and Trial Design}

Data are reported for patients treated for recurrent meningioma despite prior irradiation and for whom repeat resection alone was judged likely to be insufficient to prevent further recurrence. The patients were prospectively enrolled in a nonrandomized, all-histology clinical trial (clinicaltrials.gov, NCT03088579) at St. Joseph's Hospital and Medical Center, Phoenix, Arizona. Patients were treated from June 2013 to October 2016, with follow-up reported through June 2017. Informed consent was obtained from all study participants. For a proof-of-concept trial, we enrolled patients with disease outside the planned operative field (intracranially or extracranially). Additional enrollment criteria included planned gross-total resection (GTR), prior same-site radiation dose $\leq 100 \mathrm{~Gy}$, planned reuse of native cranium, performance status $0-1$ by the Zubrod criteria of the Eastern Cooperative Oncology Group, and life expectancy $\geq 6$ months.

\section{Implant Preparation and Operative Technique}

The number of seed sources needed to populate the anticipated postoperative bed was estimated from a preoperative MR image, and seeds were preordered to obtain 1 seed per $\mathrm{cm}^{2}$ of expected resection bed surface. Craniotomy and maximal safe resection were performed in the usual fashion. If intraoperative frozen section pathology did not confirm neoplasia, implantation was not performed.

BT implants were prepared by the radiation oncologist in the operating room during resection in the following manner. A sterilized, shielded, reusable stainless steel handheld loader (Fig. 1A; GammaTile Loader, GT Medical Technologies, Inc.) is used to position a $25 \times 25 \times 4$ $\mathrm{mm}$ lyophilized collagen square (Fig. 1B; Suturable DuraGen, Integra LifeSciences Corp.) in the loader base (Fig. 1C), the lid is closed (Fig. 1D), and Cs-131 seeds (Proxcelan, IsoRay Medical, Inc.) in Vicryl (polyglactin 910) suture (Ethicon US, LLCNJ) (Fig. 1E and F) are drawn into the collagen squares using the illustrated technique (Fig. 1C-E and G). The suture typically contains 3 seeds per strand at 1-cm intervals (Fig. 1F), and the unembedded (non-seed-containing) suture is trimmed from the collagen squares.

After the collagen square is embedded with seeds (typically 9), it is referred to as a "tile" (Fig. 2A; GammaTile, GT Medical Technologies, Inc.). The seeds are symmetrically and equally spaced within a tile when viewed from the top (Fig. 2A) but are asymmetrically spaced on end view (Fig. 2B-D) in terms of the depth from the face of the tile. The far face of a tile (i.e., seeds $3 \mathrm{~mm}$ from the tile surface, Fig. 2B and D) is typically placed in contact with the tumor bed. However, tiles can also be positioned with the near face (i.e., sources $1 \mathrm{~mm}$ from the tile surface, Fig. $2 \mathrm{~B}$ and $\mathrm{C}$ ) against the resection bed when necessary, as in patients with residual superficial tumor or implants with a small total number of sources. Tiles can be resized by cutting them with scissors when fewer seeds are required (Fig. 2E). Additional tiles are constructed as needed, depending on the size of the operative bed. Hydration does not materially change the width, length, or thickness of the collagen carrier. The embedded seeds have no noticeable impact on the inherent handling characteristics of the collagen carrier, including its malleability.

Tiles are placed on portions of the resection bed judged to be at risk for recurrence. In grade I and II meningiomas, the sites of suspected residual dural or sinus involvement or brain invasion are tiled, whereas in grade III tumors, the entire bed is addressed (Supplemental Fig. 1 and Video 1).

VIDEO 1. Brachytherapy Cs-131 tile placement in the resection bed for treatment of recurrent high-grade meningioma. Copyright Barrow Neurological Institute, Phoenix, Arizona. Published with permission. Click here to view. 
The hydrophilic nature of the collagen is typically sufficient to maintain placement, but sutures or biological adhesive is occasionally used as needed. Wound closure is accomplished in the standard fashion, with native cranium reused whenever possible. Radiation exposure in the operating room is monitored with handheld survey meters, and standard dosimeters and ring badges are worn by staff. Compliance with all applicable statutes is maintained. $\mathrm{Pa}-$ tients are given discharge instructions appropriate to the level of residual radioactivity..$^{25,26}$

\section{Assessment of Efficacy}

The RANO (Response Assessment in Neuro-Oncology) criteria were applied to evaluate the imaging responses, and progression was considered local if it occurred within $1.5 \mathrm{~cm}$ of the operative bed. ${ }^{42}$ The diagnosis was confirmed pathologically (if a subsequent surgery was performed) or by MRI (new or increased nodular enhancement despite medical management, typically corticosteroids).

\section{Postoperative Management}

Postoperative MR images and noncontrast thin-cut CT scans (0.8-1.2-mm slice thickness) for postimplantation dosimetry were typically obtained within 24 hours (Fig. 3). Dosimetry was performed using BrachyVision software (Varian Medical Systems, Inc.).

During the 1st year, follow-up visits and MR images for grade I and II tumors were typically obtained every 6 months; for grade III tumors, every 3 months. No patient was lost to follow-up.

\section{Adverse Events}

Patients were assessed at follow-up visits for toxicities according to the Common Terminology Criteria for Adverse Events (CTCAE; version 4.0; Table 1) ${ }^{39}$ Wound breakdown was defined as dehiscence without signs of infection. Patients presenting with signs of infection were classified as having wound infection, whether or not there was wound dehiscence. The diagnosis of adverse intracranial radiation-related events was made on clinical grounds and serial MRI assessment (increasing edema or nonnodular operative bed enhancement responsive to medical management).

\section{Statistical Analysis}

Analysis was performed using R (version 3.3.2, R Core Team).$^{10}$ All tumors were included in an intent-to-treat analysis, even when protocol violations occurred.

Continuous variables are summarized as median (range). Categorical variables are summarized as proportions (percentage). For median survival times, 95\% confidence intervals (CIs) were generated using a log-transformation of the variance of the product-limit (Kaplan-Meier) survival estimator.

Local time to progression (TTP) was assessed using the Cox proportional hazards models. ${ }^{38}$ We included the following variables: number of Cs-131 tiles, age, sex, radiation dose, preoperative tumor volume, surgery type, MIB-1 tumor proliferation index, and WHO tumor grade.
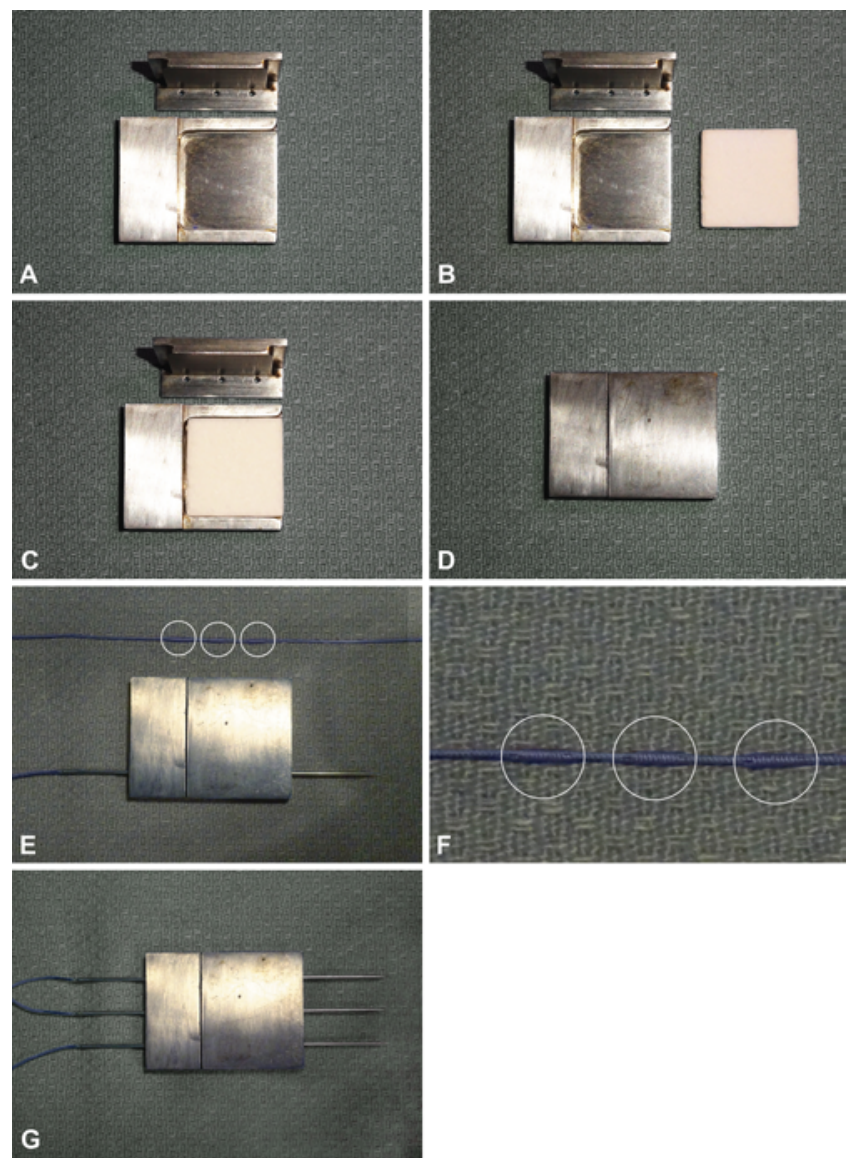

FIG. 1. A: GammaTile Loader, open, showing the base lying flat and the lid standing on end with the 3 needle-guide holes (needle-guide holes in base are not visible in this view). B: Loader as in A, with an adjacent 25 $\times 25 \times 4-\mathrm{mm}$ collagen square. C: Collagen square positioned in loader base. D: Loader, closed, with lid in position. E: The initial needle is positioned in the closed loader. Each swedged-on strand of polyglactin 910 suture contains 3 seeds (indicated by circles) at $1-\mathrm{cm}$ intervals, starting $20 \mathrm{~cm}$ from the needle tip. Each seed contains a specified amount of Cs131. F: Enlarged view of the seeds embedded in a strand of polyglactin 910 suture. G: Three needles with Cs-131 in polyglactin 910 are shown positioned in the loader. The needles are pulled through the loader, and the unembedded (non-seed-containing) suture is trimmed from the collagen square (not shown).

Effect size is given as the hazard ratio (HR; i.e., the ratio of the hazard rates between 2 groups).

All of the above variables were included in univariable and, when possible, in multivariable models to clarify the effect size of specific variables. Potential confounders included using each tumor as its own control and the inclusion of 2 tumors in 1 patient. We used clustered modeling to deal with such correlated observations and frailty modeling to account for this potential bias.

\section{Results}

Demographics and Baseline Characteristics

Of the 19 patients (median age 64.5 years, range 50-78 years), 1 patient had 2 tumors treated 3.4 years apart. All 20 tumors (i.e., cases) were implanted with Cs-131 tiles. WHO grade at the time of R+BT was grade I in 4 cases 

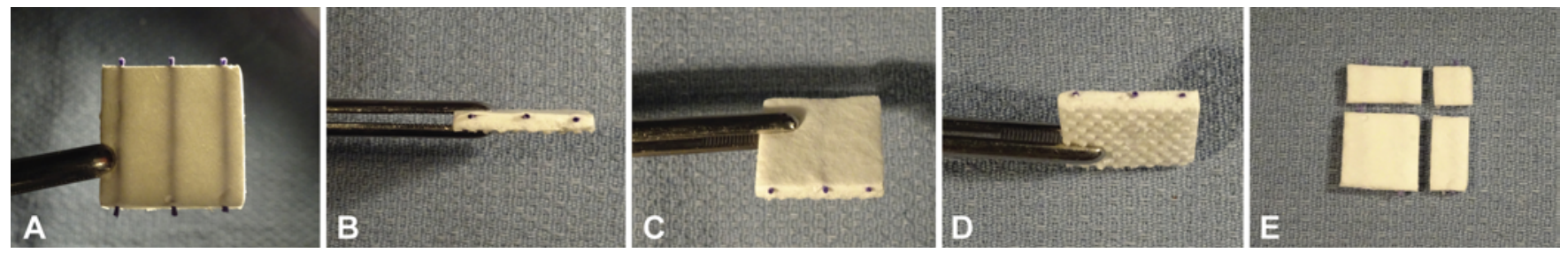

FIG. 2. A: Tile (top view) with 3 polyglactin 910 strands, each containing 3 seeds ( 9 seeds per tile) (transilluminated for clarity). B: Tile (end view) showing asymmetry of the seed strand location (3 $\mathrm{mm}$ from the near face [i.e., the part that will be in contact with the resection bed] and $1 \mathrm{~mm}$ from the far face). Also visible is the polyglactin 910 suture protruding from the ends of the tiles. C: Near face (top view). D: Far face (bottom view). E: Other tile sizes (top view) derived from initial 9 seeds per $25 \times 25 \times 4$-mm square. Clockwise from top left, tiles are shown that contain 2, 1, 2, and 4 seeds, respectively (other sizes are possible but not shown).

(20\%), grade II in $14(70 \%)$, and grade III in 2 (10\%). No patients were lost to follow-up, which remains ongoing. Table 2 summarizes the characteristics of the patients and the tumors. Details about individual patients are listed in Table 3.

Two tumors (10\%) underwent subtotal resection (STR; vs near gross-total resection [NGTR] or better), which was a deviation from the study protocol. Medical records obtained after enrollment for 1 patient showed that the cumulative dose of prior local radiotherapy was > $100 \mathrm{~Gy}$, which exceeded the cutoff point for protocol eligibility.

\section{Efficacy Outcomes}

After tile placement, local progression occurred in 2 $(10 \%)$ of the 20 tumors. At a median radiographic followup after implantation of 15.4 months (range 0.03-47.5 months), the median treatment-site TTP has not yet been reached (a 95\% CI gives a lower limit of at least 29 months) (Fig. 4). The median time to same-site local progression for the prior treatment was 18.3 months (range 3.9-32.9 months, 95\% CI 11-61 months). Progression-free survival (PFS) at 18 months was $50 \%$ with prior treatment versus $89 \%$ with R+BT. Two patients (8 and 9) had disease that progressed locally at 18 and 29 months, respectively.
At implantation, 1 patient had a grade III lesion with sarcomatous features and an MIB-1 of $30 \%$, and the other had a grade II lesion with an MIB-1 of $11 \%$. Both patients underwent NGTR resection ( $\geq 90 \%$ removal), whereas no patient with either STR or GTR had progression (Table 3).

\section{Proportional Hazards Model}

Proportional hazards modeling showed a consistent effect for Cs tiles: the HR was approximately $17 \%(\mathrm{p}=0.02$, log-rank test). The effects of age, WHO grade, and surgery were significant in single-variable models. In 2-variable models, the effect size (HR) for Cs tiles showed little variability; Cs tiles were a more significant predictor than age or extent of surgery and were a similar predictor to WHO grade. Extent of resection was not useful for modeling due to "perfect" classification (i.e., both patients with progressive disease after placement of Cs tiles underwent NGTR). Fitting MIB-1 was limited by "near-perfect" classification (i.e., 1 patient with progression had the highest recorded MIB-1, at 30\%). Sex, preoperative tumor volume, and radiation dose were not predictive of local control.

When we controlled for the potential confounders of same-tumor and same-patient observations, clustered models showed minimal effects on the HR or $\mathrm{p}$ value for
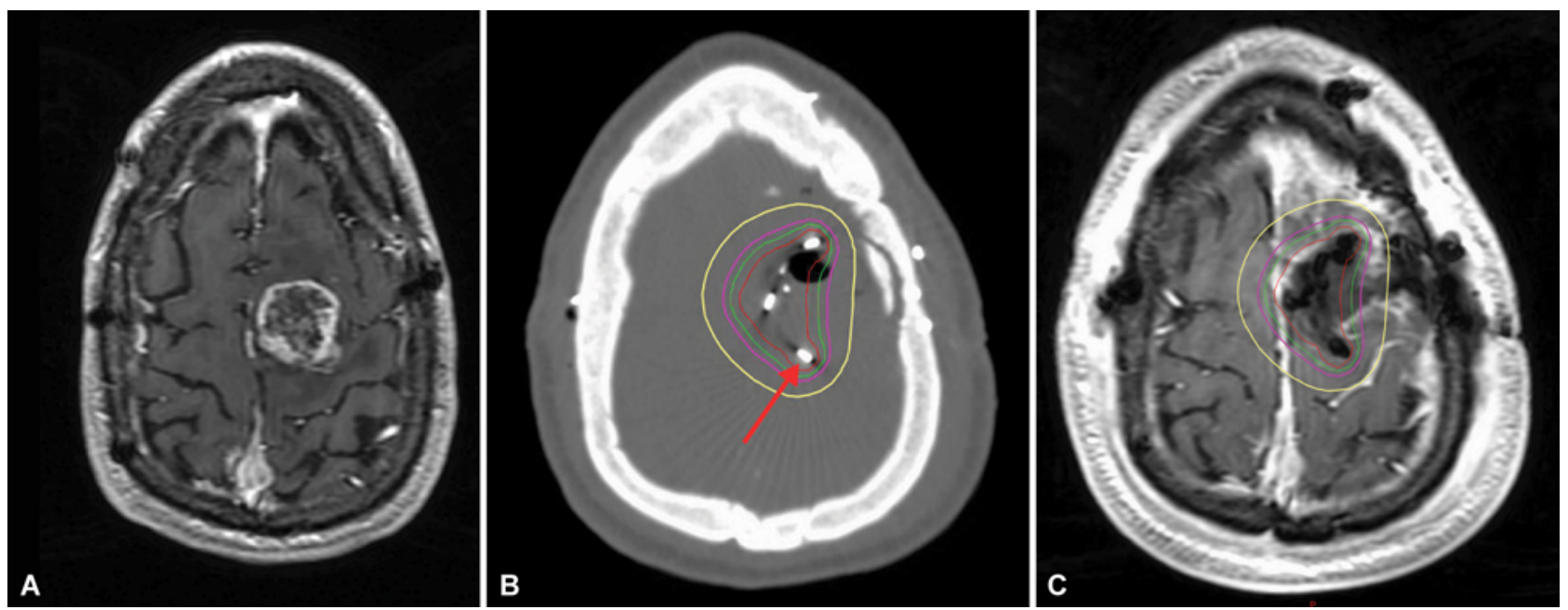

FIG. 3. Patient 3. A: Preoperative axial postcontrast T1-weighted MR image. B: Postoperative axial CT image showing dosimetry with 30- (yellow), 60- (magenta), 80- (green), and 120-Gy (red) isodose lines, and Cs-131 seeds (arrow). C: Postoperative axial postcontrast T1-weighted MR image with isodose lines as described in B and seeds appearing as small areas of signal void. 
TABLE 1. Adverse events following tumor resection with Cs-131 tile implantation

\begin{tabular}{|c|c|c|c|c|c|}
\hline \multirow[b]{2}{*}{ Complication Type } & \multicolumn{5}{|c|}{ CTCAE Grade* } \\
\hline & 1 & 2 & 3 & 4 & Pt No.† \\
\hline Alopecia & 1 & & & & 7 \\
\hline Seizures & & 1 & & & 7 \\
\hline Radiation necrosis & & & 2 & & 6,7 \\
\hline Hygroma & & & 1 & & 9 \\
\hline Wound breakdown & & & & 2 & 9,15 \\
\hline
\end{tabular}

$\mathrm{Pt}=$ patient.

* All data are numbers of adverse events unless otherwise indicated.

† For patient characteristics, see Table 3.

Cs tiles. Models with a frailty term showed the beneficial effects of Cs tiles on local progression to be greater (i.e., using a frailty term for each tumor, HR 0.09, $\mathrm{p}=0.003$ ).

\section{Survival}

At a median observation period of 19.7 months (range 1.9-48.2 months), 11 (58\%) patients remained alive. The median survival was estimated at 26 months $(95 \%$ CI 18 months-unavailable, as the upper limit was not calculable due to an insufficient number of events). The cause of death of 9 patients was remote intracranial progressive disease $(\mathrm{n}=3)$; progressive nonneurological decline $(\mathrm{n}=$ 2); and in-field intracranial progression, extracranial progression, chemotherapy-induced sepsis, and a traumatic fall $(\mathrm{n}=1$ each).

\section{Radiation Implantation and Safety}

The median time required for implantation was 6 minutes (range 2-20 minutes), as timed from the completion of resection to the completion of tile placement (Table 2). The median number of seeds implanted was 22 (range 4-57 seeds), with a median BT radiation dose of $63 \mathrm{~Gy}$ (range 54-80 Gy). The dose specification used was " $D_{90}$ " (the radiation isodose line encompassing $\geq 90 \%$ of the specified target) (Table 2). Since there are no standardized reporting radiation guidelines for brain $\mathrm{BT}$, the choice of $\mathrm{D}_{90}$ was guided by its acceptance as a standard reporting measure for Cs-131 prostate BT.

Intraoperative radiation exposure readings at the surface of the closed handheld loader (Fig. 1) with a tile and 9 seeds in place were consistently $\leq 1 \mathrm{mR} / \mathrm{hr}$. At $1 \mathrm{~m}$ from the loader, the readings were below the background radiation level of $0.03 \mathrm{mR} / \mathrm{hr}$.

\section{Adverse Events}

Table 1 summarizes treatment complications, including the CTCAE grade. In total, 4 (21\%) patients had 7 complications. Two surgeries were performed: one patient had both a hygroma and wound breakdown and another had a scalp infection. Radiation necrosis occurred in 2 of 20 implants (10\%), but neither patient required reoperation. Three patients were believed preoperatively to have progressive tumor, and they provided consent and underwent surgery; however, radiation necrosis was the only finding so they did not undergo implantation and are not included
TABLE 2. Characteristics of 19 patients with 20 tumors

\begin{tabular}{|c|c|}
\hline Variable & Value $^{*}$ \\
\hline \multicolumn{2}{|l|}{ Sex } \\
\hline Women & $10 / 19(53 \%)$ \\
\hline Men & $9 / 19(47 \%)$ \\
\hline Age at initial diagnosis, yrs & $58(41-75)$ \\
\hline Age at resection w/ Cs-131 tile implantation, yrs & $64.5(50-78)$ \\
\hline \multicolumn{2}{|l|}{ Lesion location } \\
\hline Convexity & $8 / 20(40 \%)$ \\
\hline Falcine or parafalcine & $9 / 20(45 \%)$ \\
\hline Skull base & $3 / 20(15 \%)$ \\
\hline \multicolumn{2}{|l|}{ Previous local treatments, no. } \\
\hline Resection & $2(1-4)$ \\
\hline Radiation course & $1(1-3)$ \\
\hline Preop tumor vol, $\mathrm{cm}^{3}$ & $11.3(0.9-92.0)$ \\
\hline Implant time, mins & $6(2-20)$ \\
\hline \multicolumn{2}{|l|}{ EOR when Cs-131 tiles placed } \\
\hline GTR or NGTR ( $\geq 90 \%$ resection) & $18 / 20(90 \%)$ \\
\hline STR & $2 / 20(10 \%)$ \\
\hline \multicolumn{2}{|l|}{ WHO grade at time of Cs-131 tile implantation } \\
\hline I & $4 / 20(20 \%)$ \\
\hline II & $14 / 20(70 \%)$ \\
\hline III & $2 / 20(10 \%)$ \\
\hline MIB-1, \% & $10.6(2.2-30.2)$ \\
\hline Cs-131 seeds implanted, no. & $22(4-57)$ \\
\hline Radiation dose from implant, Gy $\left(D_{90}\right)$ & $63(54-80)$ \\
\hline $\begin{array}{l}\text { Time under observation before Cs-131 implantation, } \\
\text { mos }\end{array}$ & $18.3(3.9-321.9)$ \\
\hline $\begin{array}{l}\text { Time under observation after Cs-131 implantation, } \\
\text { mos }\end{array}$ & $15.4(0.03-47.5)$ \\
\hline \multicolumn{2}{|c|}{$\begin{array}{l}D_{90}=\text { dose } 90 \text { (radiation isodose encompassing } \geq 90 \% \text { of the specified target); } \\
\text { EOR = extent of resection. } \\
{ }^{*} \text { All categorical values except patient sex and age are given on a per-case (vs } \\
\text { per-patient) basis. Continuous variables are given as median (range). Propor- } \\
\text { tions are given as fractions (percentage). }\end{array}$} \\
\hline
\end{tabular}

in the outcomes analysis. Interestingly, this 13\% (3/23) rate of preexisting radiation necrosis (e.g., preceding consideration of $\mathrm{R}+\mathrm{BT}$ ) was similar to that occurring after implantation $(10 \%, 2 / 20)$.

\section{Discussion}

We present our initial efficacy and safety experience using R+BT with Cs-131 seeds as treatment for 20 recurrent, previously irradiated, aggressive meningiomas. Our series has 2 novel aspects: 1) it represents the first published use of Cs-131 seed BT in meningiomas; and 2) it utilized seeds embedded within a biocompatible collagen tile. The tile was specifically designed to function simultaneously as a 3D spacer and a multiseed carrier, preventing seeds from harmful direct contact with the brain and facilitating rapid completion of implantation (Table 2).

Despite the clinical need, a reliably effective treatment for aggressive meningiomas that recur after irradiation is 
TABLE 3. Characteristics of individual patients, grouped by WHO grade

\begin{tabular}{|c|c|c|c|c|c|c|c|c|c|c|c|c|c|c|}
\hline $\begin{array}{l}\text { Pt } \\
\text { No. }\end{array}$ & $\begin{array}{c}\text { Age at } \\
\text { Dx/BT } \\
\text { (yrs), } \\
\text { Sex }\end{array}$ & Location & $\begin{array}{c}\text { Prior } \\
\text { SSR/ } \\
\text { SRS/ } \\
\text { IMRT } \\
\text { (no.) }\end{array}$ & $\begin{array}{l}\text { Prior } \\
\text { RT } \\
\text { Dose } \\
\text { (Gy)† }\end{array}$ & $\begin{array}{l}\text { Most Recent } \\
\text { Prior Tx }\end{array}$ & $\begin{array}{l}\text { WHO } \\
\text { Grade }\end{array}$ & $\begin{array}{c}\text { MIB-1 } \\
(\%)\end{array}$ & $\begin{array}{c}\text { Preop } \\
\text { Tumor } \\
\text { Vol } \\
\left(\mathrm{cm}^{3}\right)\end{array}$ & EOR & $\begin{array}{c}\text { BT } \\
\text { Dose, } \\
\left(D_{90}, G y\right)\end{array}$ & $\begin{array}{l}\text { TTP Pre/ } \\
\text { Post (mos) }\end{array}$ & LP $\ddagger$ & $\begin{array}{l}\text { Survival } \\
\text { Status }\end{array}$ & Cause of Death \\
\hline 7 & 49/63, M & $\mathrm{FC} / \mathrm{P}$ & $2 / 1 / 1$ & 70 & IMRT & I & 2.9 & 3.8 & GTR & 62 & $27.3 / 37.8$ & No & Alive & NA \\
\hline 13 & $41 / 50, M$ & C & $1 / 1 / 0$ & 24 & SRS (CKRS) & 1 & 2.5 & 10.4 & GTR & 60 & $70.8 / 10.4$ & No & Dead & Traumatic fall \\
\hline 15 & 47/62, M & $\mathrm{FC} / \mathrm{P}$ & $2 / 1 / 1$ & 72 & R+IMRT & 1 & 5.1 & 7.6 & NGTR & 72 & $61.4 / 19.1$ & No & Alive & NA \\
\hline 19 & $41 / 68, F$ & $\mathrm{FC} / \mathrm{P}$ & $1 / 0 / 1$ & 60 & $\mathrm{R}+\mathrm{BT}$ & I & 2.2 & 9.8 & GTR & 57 & $321.9 / 5.6$ & No & Alive & NA \\
\hline $1 a^{*}$ & $43 / 54, \mathrm{M}$ & $\mathrm{FC} / \mathrm{P}$ & $3 / 3 / 0$ & 70 & SRS (GKRS) & II & 10.6 & 11.7 & GTR & 60 & $10.6 / 47.5$ & No & Dead & Extracranial pro- \\
\hline $1 \mathrm{~b}$ & & & $1 / 1 / 0$ & 15 & SRS (GKRS) & II & 10.5 & 1.4 & GTR & 60 & $13.7 / 7.2$ & No & & gression (lung) \\
\hline 2 & $52 / 57, \mathrm{M}$ & SB & $3 / 1 / 1$ & 70 & $\mathrm{R}$ & II & 8.9 & 19.7 & GTR & 57 & $8.0 / 21.0$ & No & Dead & $\begin{array}{c}\text { Remote intracranial } \\
\text { progression }\end{array}$ \\
\hline 3 & $60 / 67, M$ & $\mathrm{FC} / \mathrm{P}$ & $3 / 1 / 0$ & 15 & SRS (GKRS) & II & 24.6 & 9.6 & GTR & 60 & $8.6 / 15.3$ & No & Dead & $\begin{array}{l}\text { Chemo-related } \\
\text { sepsis }\end{array}$ \\
\hline 4 & $67 / 72, \mathrm{~F}$ & SB & $2 / 2 / 0$ & 50 & SRS (CKRS) & II & 25.1 & 22.7 & GTR & 54 & $3.9 / 1.8$ & No & Dead & $\begin{array}{c}\text { Remote intracranial } \\
\text { progression }\end{array}$ \\
\hline 5 & $63 / 66, F$ & C & $2 / 1 / 0$ & 13 & $\begin{array}{l}\text { R+SRS } \\
\quad(\text { GKRS) }\end{array}$ & ॥ & 8.0 & 0.94 & GTR & 80 & $19.2 / 28.8$ & No & Alive & NA \\
\hline 6 & $54 / 62, \mathrm{M}$ & $\mathrm{FC} / \mathrm{P}$ & $3 / 3 / 0$ & 44 & $\mathrm{R}$ & II & 6.4 & 32.4 & GTR & 72 & $23.9 / 40.3$ & No & Alive & NA \\
\hline 8 & $59 / 70, \mathrm{~F}$ & $C$ & $1 / 1 / 0$ & 54 & IMRT & II & 11.2 & 11.8 & NGTR & 60 & $133.9 / 29.2$ & Yes & Alive & NA \\
\hline 10 & $58 / 61, \mathrm{~F}$ & C & $1 / 1 / 0$ & 25 & SRS (CKRS) & II & 17.5 & 1.4 & GTR & 58 & $26.2 / 28.7$ & No & Alive & NA \\
\hline 11 & $75 / 78, \mathrm{~F}$ & C & $2 / 0 / 1$ & 60 & $\mathrm{R}$ & II & 13 & 38.2 & GTR & 58.4 & $17.4 / 6.0$ & No & Dead & $\begin{array}{l}\text { Remote intracranial } \\
\text { progression }\end{array}$ \\
\hline 14 & 69/76, F & C & $3 / 1 / 1$ & 70 & $\mathrm{R}$ & ॥ & 11.9 & 92 & STR & 60 & $8.7 / 0.33$ & No & Dead & $\begin{array}{l}\text { Elected palliative } \\
\quad \text { care }\end{array}$ \\
\hline 16 & $66 / 73, M$ & $\mathrm{FC} / \mathrm{P}$ & $2 / 1 / 0$ & 14 & $\mathrm{R}$ & II & 16.8 & 25.1 & GTR & 66 & $9.8 / 0.03$ & No & Dead & $\begin{array}{l}\text { Elected palliative } \\
\text { care }\end{array}$ \\
\hline 17 & $66 / 74, \mathrm{~F}$ & C & $1 / 1 / 0$ & 13 & R+IMRT & II & 7.2 & 19.2 & NGTR & 80 & $7.9 / 87.4$ & No & Alive & NA \\
\hline 18 & $50 / 65, \mathrm{~F}$ & SB & $1 / 2 / 0$ & 26 & SRS (GKRS) & II & 4.2 & 10.8 & STR & 58.3 & $30.8 / 10.9$ & No & Alive & NA \\
\hline 9 & $60 / 62, \mathrm{~F}$ & $C$ & $2 / 0 / 1$ & 60 & IMRT & III & 30.2 & 11.0 & NGTR & 60 & $12.4 / 17.9$ & Yes & Dead & $\begin{array}{c}\text { Local \& remote } \\
\text { intracranial } \\
\text { progression }\end{array}$ \\
\hline 12 & $50 / 52, \mathrm{~F}$ & $\mathrm{FC} / \mathrm{P}$ & $4 / 2 / 0$ & 16 & SRS (GKRS) & III & 15.9 & 21.7 & GTR & 74 & $10.0 / 15.6$ & No & Alive & NA \\
\hline
\end{tabular}

$\mathrm{C}=$ convexity; chemo = chemotherapy; $\mathrm{CKRS}=$ CyberKnife radiosurgery; $\mathrm{Dx}=$ diagnosis; $\mathrm{FC} / \mathrm{P}=$ falx cerebri/parafalcine; GKRS = Gamma Knife radiosurgery; IMRT = intensity-modulated radiation therapy; LP = local progression of disease; NA = not applicable; $R=$ resection; $R T$ = radiation therapy; $S B=$ skull base; $S R S=$ stereotactic radiosurgery; SSR = same-site resection; TTP Pre/Post = time to progression before/after implantation of Cs-131 tiles; Tx = treatment.

${ }^{*}$ Patient 1 had 2 separate sites treated (1a and $\left.1 \mathrm{~b}\right) 3.4$ years apart.

† Prior RT doses are at implant site as total Gy, without modification for treatment type (e.g., 54-Gy EBRT, followed by 14-Gy stereotactic radiosurgery is given as 68 Gy of radiotherapy).

$\ddagger$ All 20 tumors progressed before Cs-131 tile implantation.

not currently available. When used, re-irradiation for aggressive meningiomas is typically via EBRT, using fractionated $x$-rays or stereotaxy, either after resection or as monotherapy, ${ }^{4,11,12,14,16,23,24,32}$ with some groups using protons, carbon ions, or other rarer treatments. ${ }^{9,13}$ Data on outcomes after re-irradiation of a second (or more) recurrence in aggressive meningiomas is relatively scant, $1,4,11,12,14,16,22$, 41,43 and BT for aggressive recurrent meningiomas has been reported in just a few case series, ${ }^{1,22,41}$ with all prior seed implantation series utilizing I-125. The largest BT series is from the University of California, San Francisco (UCSF), which was recently updated by Magill et al.,22 who retrospectively reported on 50 tumors in 42 patients treated be- tween 1988 and 2013 with I-125 seeds in the operative bed after resection for recurrent atypical and malignant meningioma. Since 2001, their technique has involved placing individual seeds with forceps and securing them with fibrin glue at $0.6-\mathrm{cm}$ to $1.0-\mathrm{cm}$ intervals. Median local control after implantation was 10.4 months, and overall survival was 2.4 years. Most patients $(83 \%, 35 / 42)$ had undergone prior radiation therapy and all had had at least 1 prior resection. The mean tumor volume in a prior report was 24 $\mathrm{cm}^{3} \cdot{ }^{41}$ Complications were frequent, with a $16 \%$ rate of necrosis (13\% required surgery) and a $27 \%$ rate of wound breakdown.

A second series was reported by Abou Al-Shaar et al., ${ }^{1}$ 


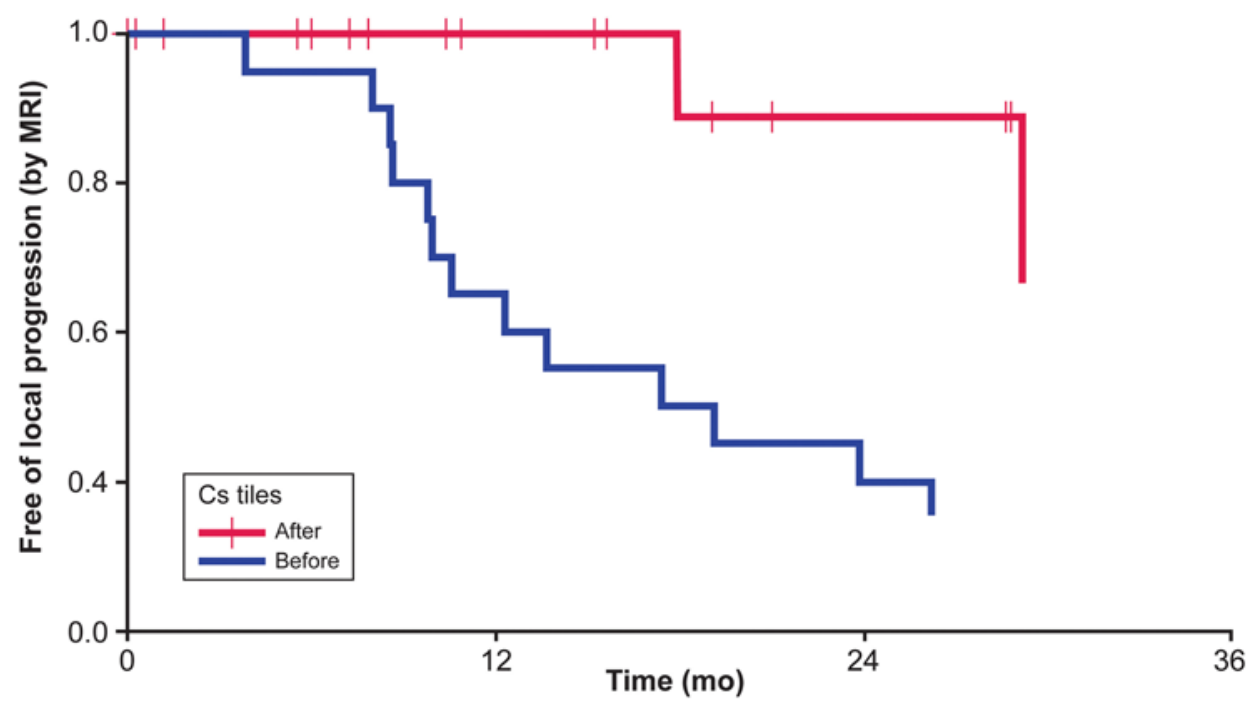

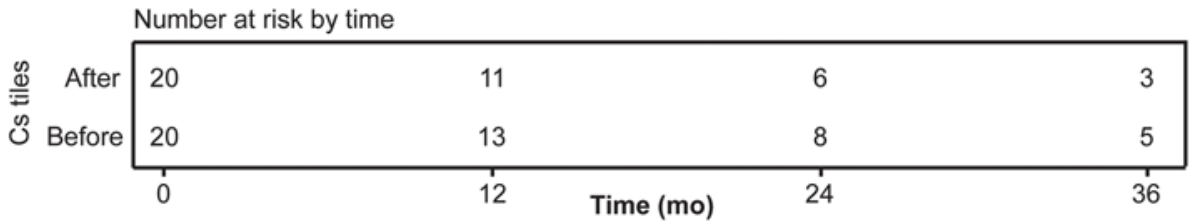

FIG. 4. Kaplan-Meier plot showing time to progression for each tumor, before and after implantation of Cs-131 tiles, for the first 3 years of observation. Vertical lines/tic marks show censoring; there are no censored observations in the "before" group, as all tumors had progressed before Cs-131 tiles were implanted. $\mathrm{HR}=0.17, \mathrm{p}=0.02$ (log-rank test).

who treated 2 patients with recurrent, previously irradiated grade II falcine meningiomas with resection and I-125 seeds pre-embedded in a flat polyglactin 910 mesh. Dose was specified as $\geq 100 \mathrm{~Gy}$ at $5 \mathrm{~mm}$ from the resection cavity surface, and both operative beds had no evidence of disease at 10 months for one patient and 31 months for the other. Both had symptomatic edema; one responded to corticosteroids and the other to bevacizumab.

Wojcieszynski et al ${ }^{43}$ utilized a variety of EBRT-based techniques in their series of 19 patients with re-treated high-grade meningiomas, achieving a median PFS of 8 months and a 1-year PFS of 17\%. Radiosurgery series for recurrent aggressive meningiomas can also serve as outcome comparisons, ${ }^{4,11,12,16,23}$ with the caveat that tumors treated with stereotactic radiosurgery are often considerably smaller and the patients may or may not have had recent resections. In these series, local 1-year control ranges from $29 \%$ to $92 \%$, with adverse radiation events of $8 \%-62 \%{ }^{4,11,12,16,23}$

Our series compares favorably to those reported in the existing literature, in terms of both the rate of radiation necrosis and the median time for same-site progression (which has not been reached at a median follow-up of 15.4 months). Surgical toxicities for the patients in our study were within the reported range for patients with intracranial neoplasms. ${ }^{17,44}$

\section{Treatment Advantages}

We believe that 3 interrelated factors contributed to the observed safety and efficacy in our series: carrier design, dose intensification, and isotope selection.

\section{Carrier Design}

Two major challenges in traditional brain seed BT have been 1) the occurrence of radiation "hot spots" and "cold spots," resulting from the uneven spacing of radiation sources; and 2) the problem of radiation injury from direct source-to-brain contact. Traditional brain seed BT requires neurosurgeons to precisely space individual radioactive seeds, cylinders measuring $4.5 \times 0.8 \mathrm{~mm}$, a difficult and time-consuming task (in the UCSF series, the average implant was 34 seeds per case; range 4-112 seeds).$^{41}$ In most reports, the implantation was done either by inserting the seeds into the brain or by gluing individual or stranded sources directly to the brain surface. $7,18,19,27$, ${ }^{30,41}$ Seeds placed too close together cause areas to receive excess radiation (hot spots), resulting in radiation injury. Conversely, spacing seeds too far apart results in areas that receive too little radiation (cold spots), potentially resulting in tumor persistence. Commercially available prepositioned seeds in suture ${ }^{27}$ or in mesh ${ }^{1}$ can lessen the seedto-seed placement variation, but they do not prevent the supratherapeutic radiation doses experienced by tissues in contact with seed sources; direct contact results in a localized dose of $\geq 2000$ Gy (200,000 rads). ${ }^{8}$ To overcome these limitations, we designed the carrier to quickly and reliably position seeds far enough off the brain surface to avoid therapeutically unnecessary radiation doses but to still achieve a clinically useful treatment depth with Cs-131 (Figs. 2 and 3). Another key element of the carrier is the ability to maintain source geometry (i.e., proper alignment and spacing) between Cs-131 seeds within a single carrier and between multiple adjacent carriers. This feature was 
important so as to be able to combine carriers when addressing large or complex operative beds. The tiles were only placed on, or adjacent to, areas deemed at surgery to be of clinical concern for recurrence (Supplemental Figs. 1 and 2 and Video 1).

\section{Dose Intensification}

The local control that we observed may result in part from the radiation dose intensification that was achieved (i.e., radiation doses that are either higher than typical or a form of radiation that has a greater relative biological effectiveness). Dose intensification is an important factor in controlling aggressive meningiomas. ${ }^{11,13,22,33}$ In our trial, two forms of dose intensification were present, one related to the isotope's half-life and one resulting from the use of BT per se. The short half-life of Cs-131 ( $\mathrm{t}_{1 / 2} 9.7$ days) results in a treatment that occurs over a relatively brief period, and more rapid dose delivery is postulated to significantly increase the relative biological effectiveness over that of longer-lived isotopes such as I-125 ( $\mathrm{t}_{1 / 2} 60$ days). ${ }^{3}$ The second form of dose intensification is a direct result of the inverse square law $^{40}$ - the intensity of radiation energy diminishes in inverse proportion to the square of the distance away from the source, leading to a proportionally much higher radiation dose close to the implant. With our carrier design and seed strength, radiation in the first few millimeters of the operative bed (the site of greatest concern for tumor residual) was 80-120 Gy (Fig. 3B and C). This dose is $1.3-2$ times greater than the 60 Gy typically achieved by fractionated EBRT, whereas the shorter range afforded by the low-energy BT isotope limited high-dose radiation to uninvolved tissues to a greater extent than achievable by intraoperative $\mathrm{x}$-ray treatments or EBRT. ${ }^{8,31,34,35}$

\section{Isotope Selection}

During protocol development, we recognized that significant volumes of brain and scalp of the enrolled patients would typically have received treatment from the prior external radiation fields. As a result, the decision was made to embed the tile carriers with the low-energy x-ray (30 $\mathrm{keV}$ ) emitter Cs-131. The isotope selection, along with the steep dose gradients inherent to BT, resulted in uninvolved intracranial structures receiving a relatively low dose compared with that with external techniques. Internal placement of low-energy sources limited the dose to extraneuronal tissues undergoing postoperative wound healing (e.g., scalp wound, cranial flap), allowing treatment to start immediately, and thereby lessening the risk of tumor recurrence associated with delay. ${ }^{6,15}$ The low energy of Cs131 also meant that during the process of tile preparation using the shielded tile loader, the radiation exposure to the operating room staff was near background levels $(<0.03$ $\mathrm{mR} / \mathrm{hr}$ ). The dense calvarial bone significantly attenuates the dose both to the incision and to caregivers, simplifying postoperative care. Thus, a closure lasting approximately 10 hours would result in an exposure to the surgeon equivalent to that of a chest radiograph. Similar results have been reported by others using this isotope. ${ }^{27}$

\section{Study Limitations}

Our findings have several potential limitations, given the single-arm, single-institution nature of this trial. The prior time to same-site local progression as a comparison to the study outcome (Fig. 4) was included post hoc after reviewing the literature on time to progression after re-irradiation of recurrent meningiomas, , $, 4,11,12,14,16,22,41,43$ which showed highly variable published historical outcomes. Although biases exist in all comparisons, we believe that this internal comparison (i.e., time to local recurrence of prior treatment vs study treatment in the same patient cohort, at the same site, for the same tumor, and with the same care team) was as reasonable a comparator for this exploratory trial as the available historical literature. Another confounder, due to the lack of a control group, is that some tumors may have achieved local control due to the repeat surgery alone. We believe that this phenomenon is unlikely to be the case for most patients, as all 19 had recurrent tumors, with prior same-site surgery that had failed once or more in every case.

With any single-institution trial, the potential for technical generalizability may raise questions. There were multiple neurosurgical users, and all became adept at tile placement almost immediately, largely because of an existing familiarity with the handling properties of the carrier material (lyophilized collagen). Tile construction was quickly mastered by the radiation oncologist, resulting in a precise and reproducible tile, albeit labor intensive. Reporting on a subset of a study's enrolled patients can either overestimate or underestimate the utility of the reported therapy. The cohort we are reporting on, patients with recurrent, previously irradiated, aggressive meningioma, comprised a substantial number of the initially treated patients and presented an opportunity to examine the results in a specific tumor type. We are planning single histology trials utilizing a commercially produced tile pre-embedded with the Cs isotope.

\section{Conclusions}

The combination of R+BT with collagen tiles embedded with Cs-131 seed sources resulted in excellent local control with minimal side effects in this group of patients with recurrent, previously irradiated, aggressive meningiomas. Our experience suggests that this treatment was time efficient and straightforward to administer and could help widen the appeal and availability of adjuvant intracranial BT.

\section{Acknowledgments}

This work was supported by grants from the Arizona Commerce Authority, Phoenix, Arizona, \#AZFG 2013-10 and \#AZFG 2014-05, and by the Foundation for Cancer Research and Education, Gilbert, Arizona.

We thank the staff of Neuroscience Publications at Barrow Neurological Institute for assistance with manuscript preparation.

\section{References}

1. Abou Al-Shaar H, Almefty KK, Abolfotoh M, Arvold ND, Devlin PM, Reardon DA, et al: Brachytherapy in the treatment of recurrent aggressive falcine meningiomas. J Neurooncol 124:515-522, 2015

2. Aizer AA, Bi WL, Kandola MS, Lee EQ, Nayak L, Rinne ML, et al: Extent of resection and overall survival for patients 
with atypical and malignant meningioma. Cancer 121:43764381, 2015

3. Armpilia CI, Dale RG, Coles IP, Jones B, Antipas V: The determination of radiobiologically optimized half-lives for radionuclides used in permanent brachytherapy implants. Int J Radiat Oncol Biol Phys 55:378-385, 2003

4. Attia A, Chan MD, Mott RT, Russell GB, Seif D, Daniel Bourland J, et al: Patterns of failure after treatment of atypical meningioma with gamma knife radiosurgery. J Neurooncol 108: 179-185, 2012

5. Blonigen BJ, Steinmetz RD, Levin L, Lamba MA, Warnick RE, Breneman JC: Irradiated volume as a predictor of brain radionecrosis after linear accelerator stereotactic radiosurgery. Int J Radiat Oncol Biol Phys 77:996-1001, 2010

6. Burnet NG, Jena R, Jefferies SJ, Stenning SP, Kirkby NF: Mathematical modelling of survival of glioblastoma patients suggests a role for radiotherapy dose escalation and predicts poorer outcome after delay to start treatment. Clin Oncol (R Coll Radiol) 18:93-103, 2006

7. Chen AM, Chang S, Pouliot J, Sneed PK, Prados MD, Lamborn KR, et al: Phase I trial of gross total resection, permanent iodine-125 brachytherapy, and hyperfractionated radiotherapy for newly diagnosed glioblastoma multiforme. Int $\mathbf{J}$ Radiat Oncol Biol Phys 69:825-830, 2007

8. Chiu-Tsao ST, Napoli JJ, Davis SD, Hanley J, Rivard MJ: Dosimetry for 131Cs and 125I seeds in solid water phantom using radiochromic EBT film. Appl Radiat Isot 92:102-114, 2014

9. Combs SE, Kessel K, Habermehl D, Haberer T, Jäkel O, Debus J: Proton and carbon ion radiotherapy for primary brain tumors and tumors of the skull base. Acta Oncol 52:15041509,2013

10. Dardis C, Woolf EC, Scheck AC: Towards reproducible research: from data analysis (in $\mathrm{R}$ ) to a typeset laboratory notebook (as .pdf) using the text editor Emacs with the 'mp' package [v1]. F1000Res 4: 2015

11. Ding D, Starke RM, Hantzmon J, Yen CP, Williams BJ, Sheehan JP: The role of radiosurgery in the management of WHO Grade II and III intracranial meningiomas. Neurosurg Focus 35(6):E16, 2013

12. Ferraro DJ, Funk RK, Blackett JW, Ju MR, DeWees TA, Chicoine MR, et al: A retrospective analysis of survival and prognostic factors after stereotactic radiosurgery for aggressive meningiomas. Radiat Oncol 9:38, 2014

13. Gerster-Gilliéron K, Forrer F, Maecke H, Mueller-Brand J, Merlo A, Cordier D: 90Y-DOTATOC as a therapeutic option for complex recurrent or progressive meningiomas. J Nucl Med 56:1748-1751, 2015

14. Hug EB, Devries A, Thornton AF, Munzenride JE, Pardo FS, Hedley-Whyte ET, et al: Management of atypical and malignant meningiomas: role of high-dose, 3D-conformal radiation therapy. J Neurooncol 48:151-160, 2000

15. Iorio-Morin C, Masson-Côté L, Ezahr Y, Blanchard J, Ebacher A, Mathieu D: Early Gamma Knife stereotactic radiosurgery to the tumor bed of resected brain metastasis for improved local control. J Neurosurg 121 Suppl:69-74, 2014

16. Kaul D, Budach V, Wurm R, Gruen A, Graaf L, Habbel P, et al: Linac-based stereotactic radiotherapy and radiosurgery in patients with meningioma. Radiat Oncol 9:78, 2014

17. Klinger DR, Flores BC, Lewis JJ, Hatanpaa K, Choe K, Mickey B, et al: Atypical meningiomas: recurrence, reoperation, and radiotherapy. World Neurosurg 84:839-845, 2015

18. Koot RW, Maarouf M, Hulshof MC, Voges J, Treuer H, Koedooder C, et al: Brachytherapy: results of two different therapy strategies for patients with primary glioblastoma multiforme. Cancer 88:2796-2802, 2000

19. Larson DA, Suplica JM, Chang SM, Lamborn KR, McDermott MW, Sneed PK, et al: Permanent iodine 125 brachy- therapy in patients with progressive or recurrent glioblastoma multiforme. Neuro Oncol 6:119-126, 2004

20. Lecchi M, Fossati P, Elisei F, Orecchia R, Lucignani G: Current concepts on imaging in radiotherapy. Eur J Nucl Med Mol Imaging 35:821-837, 2008

21. Lukens JN, Gamez M, Hu K, Harrison LB: Modern brachytherapy. Semin Oncol 41:831-847, 2014

22. Magill ST, Lau D, Raleigh DR, Sneed PK, Fogh SE, McDermott MW: Surgical resection and interstitial iodine-125 brachytherapy for high-grade meningiomas: a 25 -year series. Neurosurgery 80:409-416, 2017

23. Milosevic MF, Frost PJ, Laperriere NJ, Wong CS, Simpson WJ: Radiotherapy for atypical or malignant intracranial meningioma. Int J Radiat Oncol Biol Phys 34:817-822, 1996

24. National Comprehensive Cancer Network (NCCN): NCCN clinical practice guidelines in oncology: central nervous system cancers, version 1.2016. NCCN.org. (http://www.ncen. org/professionals/physician_gls/PDF/cns.pdf) [Accessed August 24, 2018]

25. National Council on Radiation Protection and Measurements (NCRP): Report no. 116-limitation of exposure to ionizing radiation (supersedes NCRP report no. 91). NCRPonline. org. (https://ncrponline.org/product/report-no-116-limitationof-exposure-to-ionizing-radiation-supersedes-ncrp-reportno-91-1993/) [Accessed August 26, 2018]

26. Nuclear Regulatory Commission (NRC): Release of Patients Administered Radioactive Materials, NUREG 1556, Vol. 9, Rev. 2, Appendix U. Washington, DC: NRC, 2016

27. Parashar B, Wernicke AG, Pavese A, Singh P, Trichter S, Sabbas A, et al: Cesium-131 permanent seed brachytherapy: dosimetric evaluation and radiation exposure to surgeons, radiation oncologists, and staff. Brachytherapy 10:508-513, 2011

28. Pham A, Yondorf MZ, Parashar B, Scheff RJ, Pannullo SC, Ramakrishna R, et al: Neurocognitive function and quality of life in patients with newly diagnosed brain metastasis after treatment with intra-operative cesium-131 brachytherapy: a prospective trial. J Neurooncol 127:63-71, 2016

29. Pinker K, Noebauer-Huhmann IM, Stavrou I, Hoeftberger R, Szomolanyi P, Karanikas G, et al: High-resolution contrastenhanced, susceptibility-weighted MR imaging at $3 \mathrm{~T}$ in patients with brain tumors: correlation with positron-emission tomography and histopathologic findings. AJNR Am J Neuroradiol 28:1280-1286, 2007

30. Prados MD, Gutin PH, Phillips TL, Wara WM, Sneed PK, Larson DA, et al: Interstitial brachytherapy for newly diagnosed patients with malignant gliomas: the UCSF experience. Int J Radiat Oncol Biol Phys 24:593-597, 1992

31. Purdy JA: Dose to normal tissues outside the radiation therapy patient's treated volume: a review of different radiation therapy techniques. Health Phys 95:666-676, 2008

32. Rogers L, Gilbert M, Vogelbaum MA: Intracranial meningiomas of atypical (WHO grade II) histology. J Neurooncol 99:393-405, 2010

33. Rogers LR, Rock JP, Sills AK, Vogelbaum MA, Suh JH, Ellis TL, et al: Results of a phase II trial of the GliaSite radiation therapy system for the treatment of newly diagnosed, resected single brain metastases. J Neurosurg 105:375-384, 2006

34. Ruge MI, Kocher M, Maarouf M, Hamisch C, Treuer H, Voges J, et al: Comparison of stereotactic brachytherapy (125 iodine seeds) with stereotactic radiosurgery (LINAC) for the treatment of singular cerebral metastases. Strahlenther Onkol 187:7-14, 2011

35. Schueller P, Palkovic S, Moustakis C, Kónemann S, Wassmann $\mathrm{H}$, Willich $\mathrm{N}$ : Clinical results and isodose planning of neuronavigation-guided intraoperative radiotherapy (IORT) in 77 brain tumor patients: adequate target volume coverage improves results. Rev Cancer (Madrid) 22(extra):58, 2008

36. Shrieve D, Gutin P, Larson D: Brachytherapy, in Mauch PM, 
Loeffler JS (eds): Radiation Oncology Technology and Biology. Philadelphia: WB Saunders, 1994, pp 216-236

37. Stewart FA: Re-treatment after full-course radiotherapy: is it a viable option? Acta Oncol 38:855-862, 1999

38. Therneau TM, Grambsch P: Modeling Survival Data: Extending the Cox Model. New York: Springer, 2000

39. US Department of Health and Human Services (USDHHS): Common Terminology Criterion for Adverse Events (CTCAE) Version 4.0. Bethesda, MD: USDHHS, 2009. (https://evs.nci.nih.gov/ftp1/CTCAE/CTCAE_4.03/Archive/ CTCAE_4.0_2009-05-29_QuickReference_8.5x11.pdf) [Accessed August 26, 2018]

40. Vitaz TW, Warnke PC, Tabar V, Gutin PH: Brachytherapy for brain tumors. J Neurooncol 73:71-86, 2005

41. Ware ML, Larson DA, Sneed PK, Wara WW, McDermott MW: Surgical resection and permanent brachytherapy for recurrent atypical and malignant meningioma. Neurosurgery 54:55-64, 2004

42. Wen PY, Macdonald DR, Reardon DA, Cloughesy TF, Sorensen AG, Galanis E, et al: Updated response assessment criteria for high-grade gliomas: Response Assessment in Neuro-Oncology Working Group. J Clin Oncol 28:19631972, 2010

43. Wojcieszynski AP, Ohri N, Andrews DW, Evans JJ, Dicker AP, Werner-Wasik M: Reirradiation of recurrent meningioma. J Clin Neurosci 19:1261-1264, 2012

44. Wong JM, Panchmatia JR, Ziewacz JE, Bader AM, Dunn IF, Laws ER, et al: Patterns in neurosurgical adverse events: intracranial neoplasm surgery. Neurosurg Focus 33(5):E16, 2012

\section{Disclosures}

Drs. Brachman, Youssef, Zabramski, Smith, McBride, and Nakaji and Ms. Thomas are shareholders in GT Medical Technologies, Inc. Drs. Brachman, Youssef, McBride, and Najaki and Ms. Thomas are co-founders and consultants at GT Medical Technologies, Inc. Dr. Brachman is the Chief Technology Officer at GT Medical Technologies, Inc. Dr. Little has ownership in Kogent and stock options in Spiway.

\section{Author Contributions}

Conception and design: Nakaji, Brachman, Youssef, Thomas, McBride. Acquisition of data: all authors. Analysis and interpretation of data: Nakaji, Brachman, Youssef, Dardis, Thomas, McBride. Drafting the article: Nakaji, Brachman, Youssef, Dardis, Thomas, McBride, Sorensen. Critically revising the article: Nakaji, Brachman, Youssef, Dardis, Thomas, McBride, Sorensen. Reviewed submitted version of manuscript: all authors. Approved the final version of the manuscript on behalf of all authors: Nakaji. Statistical analysis: Brachman, Youssef, Dardis. Administrative/ technical/material support: Nakaji, Brachman, Youssef, Thomas. Study supervision: Nakaji, Brachman, Youssef, Thomas.

\section{Supplemental Information \\ Videos}

Video 1. https://vimeo.com/286159099.

Online-Only Content

Supplemental material is available with the online version of the article.

Supplemental Figs. 1 and 2. https://thejns.org/doi/suppl/10. 3171/2018.7.JNS18656.

\section{Previous Presentations}

Portions of the work were presented in oral form at the Society for Neuro-Oncology Conference on Meningioma, Toronto, Ontario, Canada, June 17, 2016.

\section{Correspondence}

Peter Nakaji: c/o Neuroscience Publications, Barrow Neurological Institute, St. Joseph's Hospital and Medical Center, Phoenix, AZ. neuropub@barrowneuro.org. 